\title{
Risk factors associated with Cardiovascular Disease (CVD) in Thailand from the 4th National Health Examination Survey 2008-2009
} \author{
Mubarak Ishmael ${ }^{2}$ \\ 'Loei Rajabhat University, Department of Public Health, Thailand \\ ${ }^{2}$ Faculty of Health and Wellbeing, Sheffield Hallam University, Sheffield SIO 2BP, UK \\ ${ }^{3}$ Department of Arts and Sciences, Elson Hall 25I Zanesville, OH 4370I, Ohio University, USA \\ ${ }^{4}$ Department of Engineering and Mathematics, Sheffield Hallam University, Sheffield, SI IWB, UK
}

Rungkarn Inthawong, ${ }^{1}$ Khaled Khatab, ${ }^{2,3}$ Malcolm Whitfield, ${ }^{2}$ Karen Collins, ${ }^{2}$ Maruf A. Raheem ${ }^{4}$ and

Correspondence: Khaled Khatab, Email k.khatab@shu.ac.uk

Received: December 10, 2018 | Published: January 25, 2019

Copyright@ 2019 Inthawong et al. This is an open access article distributed under the terms of the Creative Commons Attribution License, which permits unrestricted use distribution, and reproduction in any medium, provided the original author and source are credited.

\begin{abstract}
Objectives: This study aims to describe the current situation of Cardiovascular Disease (CVD) and to explore the association of the modifiable risk factors with Coronary heart disease (CHD) and stroke in Thailand.

Methods: The 4th National Health Examination Survey (NHESIV) dataset has been used in this study. 19,342 participants aged $\geq 15$ years have completed the data gathering process on CVD risk factors have been included in the analysis, which comprises 9,246 men and 10,096 women. The descriptive statistic, the bivariate analysis and the multiple logistic regression have been performed to describe and explore the association among CVD risk factors, CHD and stroke. The modifiable risk factors included in the analysis are age, BMI, total cholesterol, triglyceride, high-density lipoprotein cholesterol (HDL-C), systolic blood pressure (SBP), diabetes and regular smoking.

Results: The mean age of the participants is 52.7 years. The prevalence of CHD was $2.5 \%$ in men, and $2.3 \%$ in women and the prevalence of stroke was $2.5 \%$ in men and $1.6 \%$ in women. The overall prevalence of diabetes was $10.1 \%$, and regular smoking was $17.9 \%$. When exploring the association of the modifiable risk factors with CHD and stroke, using the bivariate and multivariate analysis, the results show that factors associated with both CHD and stroke are being aged 55 and over, high blood pressure and diabetes. Obesity, high triglyceride level and low HDL-C, only showed association with CHD but does not show any significant association to stroke. Having a high triglyceride level was related to stroke just in women but does not show any association in men. The factors that do not show significant association in both CHD and stroke are high total cholesterol and being a regular smoker.
\end{abstract}

Conclusions: Although the analysis of the cross-sectional data was not able to identify the cause and effect of the factors relating to CHD or stroke, it showed some association with these modifiable risk factors for CVD. The modifiable risk factors, such as high blood pressure, obesity and diabetes need to be of concern in considering the CVD prevention strategies in Thailand

\section{Introduction}

CVD has become the leading causes of death and disability in Thailand. ${ }^{1}$ The number of patients who were admitted to hospital with CVD conditions has increased year on year. ${ }^{2}$ Over the past decade, the modifiable risk factors, such as obesity, dyslipidemia, systolic blood pressure, diabetes and regular smoking, have been proved to be associated with the cause of CVD in many studies. ${ }^{3-8}$ The increase of CVD patients in Thailand may be caused by changes in lifestyles, such as being less physically active and having an unhealthy diet, which leads to an increase in the level of metabolic risk factors of the individual. ${ }^{9}$ The EGAT study, which was a CVD cohort study in Thailand, found that the trend of the mean level of CVD risk factors such as SBP, BMI, total cholesterol, HDL-C and the prevalence of diabetes, increased over a 12 -year follow-up period, ${ }^{10}$ whereas the prevalence of regular smoking declined. ${ }^{11}$ Although it is well known that these modifiable risk factors are related to CVD conditions, the metabolic risk factors may change over time. This article presents the results from the descriptive analysis of the risk factors for CVD. This study aims to describe the current situation of CVD and explore the risk factors that are associated with CVD conditions, such as CHD and stroke, especially in Thailand. The CVD conditions referred to in this chapter are CHD and stroke

\section{Material and Methods}

The 4th National Health Examination Survey (NHESIV) Thailand is a cross-sectional, population-based survey which was conducted in 2008-2009. ${ }^{9}$ The primary objective of this survey is to present the prevalence of chronic diseases and the potential health risk factors to the Thai population. This survey is a national representative of the Thai health status by age, gender, administrative area (urban/rural) and geographic regions. Stratified four stage random sampling has been applied to the sampling in the Thai population, at the age of 1 year and above, in 20 provinces and the Bangkok metropolitan area.
Submit your Article / www.ologyjournals.com/submit-article OP, Ology 
The survey sampling was divided into three age groups, 1-14 years, $15-59$ years old and 60 years old and above for both sexes. This survey recruited 20,450 adults who were aged $15-59$ years and 60 years and above to represent the health status in both the labour force and the elderly. The sampling method has been described elsewhere. ${ }^{9}$ The data has been collected by interview using a questionnaire, physical examination, blood examination and urine examination.

The anonymous secondary dataset has been collected from the National Health Examination survey office, National Health System Research Institute, Thailand. Full permission was granted including ethical approval to allow access to data to use in this study. Of 20,450 participants aged 15 years and above, 19,342 participants have been included in the analysis. 1,108 participants have been excluded from this analysis because the data was incomplete. The descriptive analysis has been performed on the four main classical risk factors for CVD, such as body mass index (BMI), lipid profiles (total cholesterol, triglyceride, HDL and LDL), systolic blood pressure and regular smoking. It has been descriptively analysed for CVD related conditions that have been reported in participants in the survey, such as hypertension, diabetes mellitus, CHD and stroke. Multiple logistic regressions have been performed to explore the association between these risk factors and CVD conditions.

\section{The outcome variables}

For the outcome variables, we've used the same definition as that of the National Health Examination Survey IV. The outcome variables are:

\section{Coronary heart disease (CHD)}

Coronary heart disease (CHD)is a condition where there is thickening of the coronary artery wall. ${ }^{12}$ It is also known as atherosclerosis, ischemic heart disease (IHD) or coronary artery disease (CAD). ${ }^{13}$ Atherosclerosis is the restriction of the blood supply to the heart due to either a blood clot or blockage in the circulation system. ${ }^{14}$ The progression of CHD which often presents in clinical practice includes angina, acute coronary syndromes (ACS), myocardial infarction, ischemic cardiomyopathy, chronic heart failure and sudden cardiac death. Patients with CHD conditions may get the initial symptom of having chest pains which may be stable or unstable angina pectoris. Then, it is likely to develop to the next state, which is called acute

Table I The general characteristic of the NHESIV participants aged $\geq 15$ years classified by risk factors of CVD and gender coronary syndrome (ACS).$^{15}$ ACS covers unstable angina and myocardial infarction. The symptoms are prolonged ischemic chest pains which are not relieved by rest. Myocardial infarction (commonly known as a heart attack), occurs when there is a blood flow reduction, which may lead to chronic conditions such as intracoronary thrombosis, platelet aggregation and heart attack. ${ }^{16}$ The typical initial symptoms of myocardial infarction are central chest pains or the feeling of discomfort in the chest, arms, left shoulder, elbows, jaw or back. The person having a heart attack may experience difficulty in breathing, nausea or vomiting. This may then result in heart failure or sudden death. Individuals who get CHD conditions can move from one event to another event because there are different endpoints for the CHD developing process. It is important to consider that these events are interrelated to each other. ${ }^{12}$

\section{Stroke}

Stroke or cerebrovascular disease is a condition that occurs when there is an interruption of blood supply to the brain which may result in neurological symptoms. ${ }^{17}$ There are two major types of stroke which are an ischemic or haemorrhagic stroke. The former occurs when there is inadequate blood supply to some part of the brain caused by an obstruction in a blood vessel to the brain, thrombosis or embolism. ${ }^{18}$ The latter occurs as spontaneous bleeding into the brain which is associated with hypertension. ${ }^{19}$ Both types can lead to an acute loss of brain function and disability. The signs and symptoms of a stroke are the weakness of the facial muscles, arms and/or legs on either side of the body. ${ }^{13}$ Depending on the region within the brain that the stroke occurs, the person may have difficulties such as limitations in movement, loss of speech, loss of sensation and visual field defect. ${ }^{17}$ The symptoms may last for more than 24 hours or lead to death. However, if the duration of the symptoms lasts for less than 24 hours, it is often referred to as a transient ischemic attack (TIA). ${ }^{12,20}$

\section{Results}

Table 1 shows the general character of the NHESIV participants aged $\geq 15$ years. There were 9,246 men and 10,096 women included in the analysis. $20.8 \%$ of participants are at aged 55 to 64 years. Although $60.4 \%$ of men and $50.6 \%$ of women had normal BMI levels (BMI $18.5-<25 \mathrm{~kg} / \mathrm{m} 2$ ), $22.2 \%$ of men and $29.2 \%$ of women were overweight (BMI $25-<30 \mathrm{~kg} / \mathrm{m} 2$ ). Additionally, $5.6 \%$ of men and $11.4 \%$ of women were obese (BMI $\geq 30 \mathrm{~kg} / \mathrm{m} 2$ ).

\begin{tabular}{llll}
\hline Risk factors & Men $(n=9,246)$ & Women $(n=10,096)$ & Total $(n=19,342)$ \\
\hline Age groups (years) & & & \\
$15-24$ & $9.9 \%(919)$ & $8.3 \%(834)$ & $9.1 \%(1,753)$ \\
$25-34$ & $9.6 \%(889)$ & $9.5 \%(962)$ & $9.6 \%(1,851)$ \\
$35-44$ & $13.9 \%(1,287)$ & $15.7 \%(1,581)$ & $14.8 \%(2,868)$ \\
$45-54$ & $13.6 \%(1,256)$ & $15.9 \%(1,600)$ & $14.8 \%(2,856)$ \\
$55-64$ & $20.8 \%(1,920)$ & $20.8 \%(2,096)$ & $20.8 \%(4,016)$ \\
$65-74$ & $21.4 \%(1,975)$ & $19.5 \%(1,969)$ & $20.4 \%(3,944)$ \\
$\geq 75$ & $10.8 \%(1,000)$ & $10.44(1,054)$ & $10.6 \%(2,054)$
\end{tabular}

Citation: Inthawong R, Khatab K, Whitfield M, et al. Risk factors associated with Cardiovascular Disease (CVD) in Thailand from the 4th National Health Examination Survey 2008-2009. Biostatistics Epidemiol Int J. (2019);2(I):I3-22. DOI: $10.3088 \mid /$ beij.000I4 


\section{(Table I continue..)}

BMI categories $\left(\mathrm{kg} / \mathrm{m}^{2}\right)$

$<18.5$

$18.5-<25$

$25-<30$

$\geq 30$

High total cholesterol (TC $\geq 200 \mathrm{mg} / \mathrm{dL})$

No

Yes

High triglyceride $(\mathrm{TG} \geq 150 \mathrm{mg} / \mathrm{dL})$

No

Yes

Low HDL-C $(<40 \mathrm{mg} / \mathrm{dL}$ in male and $<50 \mathrm{mg} /$ $\mathrm{dL}$ in female)

No

Yes

High blood pressure

No

Yes

Diabetes mellitus

No

Yes

Regular smoking

No

Yes
II. $8 \%(1,090)$

$60.4 \%(5,584)$

$22.2 \%(2,054)$

$5.6 \%(518)$

$48.9 \%(4,519)$

$51.1 \%(4,727)$

$61.2 \%(5,654)$

$38.9 \%(3,592)$

$65.0 \%(6,014)$

$35.0 \%(3,232)$

$66.7 \%(6,168)$

$33.3 \%(3,078)$

$90.7 \%(8,384)$

$9.3 \%(862)$

$65.6 \%(6,062)$

$34.4 \%(3,184)$
$8.8 \%(885)$

$50.6 \%(5,106)$

$29.2 \%(2,952)$

II.4\%(I,153)

$39.5 \%(3,989)$

$60.5 \%(6,107)$

$66.1 \%(6,669)$

$33.9 \%(3,427)$

$63.7 \%(12,323)$

$36.3 \%(7,019)$

$42.3 \%(4,273)$

$53.2 \%(10,287)$

$57.7 \%(5,823)$

$46.8 \%(9,055)$

$68.1 \%(6,873)$

$67.4 \%(|3,04|)$

$31.9 \%(3,223)$

$32.6 \%(6,30 \mathrm{I})$

$89.1 \%(9,000)$

$89.9 \%(17,384)$

$10.9 \%(1,096)$

$10.1 \%(1,958)$

$97.3 \%(9,820)$

$82.1 \%(15,882)$

$2.7 \%(276)$
Regarding the lipid profile, $51.1 \%$ of men and $60.5 \%$ of women had high total cholesterol levels. $38.9 \%$ of men and $33.9 \%$ of women had high triglyceride level. Furthermore, $35 \%$ of men and $57.7 \%$ of women had low levels of the HDL-C which is considered as a risk for CVD.

Moreover, $33.3 \%$ of men and $31.9 \%$ of women had high blood pressure. $9.3 \%$ of men and $10.9 \%$ of women had diabetes. $34.4 \%$ of men were current regular smokers, whereas, $2.7 \%$ of women were regular smokers.
Table 2 presents the prevalence of CHD and Stroke in the National Health Examination Survey for participants aged 15 years and over, classified by risk factors of CVD. The modified risk factors are gender, age groups, BMI categories, high total cholesterol, high triglyceride, low HDL-C, high blood pressure, diabetes and regular smoking. For CHD, the prevalence of this in men is $2.5 \%$ and in women is $2.3 \%$. The prevalence increases respectively with an increase of the age groups. The highest prevalence of CHD is $5.3 \%$ in participants who are aged over 75 years old. The lowest prevalence of CHD is $0.2 \%$ in ages 15-24 years and 25-34 years.

Table 2 The prevalence of CHD and Stroke (\%) classified by risk factors in the NHESIV participants aged $\geq 15$ years

\begin{tabular}{llll}
\hline Risk factors & $\mathbf{N}(\mathbf{N}=19,342)$ & CHD $(\mathbf{n}=466)$ & STROKE $(\mathbf{n}=\mathbf{3 9 5})$ \\
\hline Gender & & & \\
Men & 9,246 & $2.5 \%(233)$ & $2.5 \%(234)$
\end{tabular}


(Table 2 continue..)

Women

Age groups (years)

15-24

25-34

$35-44$

$45-54$

$55-64$

$65-74$

$\geq 75$

BMl categories $\left(\mathrm{kg} / \mathrm{m}^{2}\right)$

$<18.5$

$18.5-<25$

$25-<30$

$\geq 30$

High total cholesterol

(TC $\geq 200 \mathrm{mg} / \mathrm{dL}$ )

No

Yes

High triglyceride (TG $\geq 150 \mathrm{mg}$ /

dL)

No

Yes

Low HDL-C $(<40 \mathrm{mg} / \mathrm{dL}$ in men and $<50 \mathrm{mg} / \mathrm{dL}$ in women)

No

Yes

High blood pressure

No

Yes

Diabetes mellitus

No

Yes

Regular smoking

No

Yes
10,096

I,753

$|, 85|$

2,868

2,856

4,016

3,944

2,054

I,975

10,690

5,006

$|, 67|$

8,508

10,834

12,323

7,019

10,287

9,055

$|3,04|$

6,301

17,384

I,958

15,882

3,460
$2.3 \%(233)$

$1.6 \%(16 I)$

$0.2 \%(4)$

$0.3 \%(6)$

$0.2 \%(4)$

$0.4 \%(8)$

$0.8 \%(24)$

I. $2 \%(33)$

$1.4 \%(39)$

$2.7 \%(110)$

$3.5 \%(139)$

$3.7 \%(75)$

$5.3 \%(109)$

$1.8 \%(36)$

$2.6 \%(5 I)$

2\%(209)

$1.9 \%(199)$

$3.2 \%(160)$

$2.3 \%(115)$

$3.7 \%(6 I)$

$1.8 \%(30)$

$2.7 \%(228)$

$2 \%(170)$

$2.2 \%(238)$

$2.1 \%(225)$

$2.2 \%(27 I)$

I.7\%(2।4)

$2.8 \%(195)$

$2.6 \%(18 I)$

$2.1 \%(2 \mid 5)$

$1.9 \%(198)$

$2.7 \%(25 I)$

$2.2 \%(197)$

I.3\%(I70)

I.3\%(169)

$4.7 \%(296)$

$3.6 \%(226)$

$1.9 \%(338)$

I.8\%(308)

$6.5 \%(128)$

$4.4 \%(87)$
$2.6 \%(420)$

$2.1 \%(34 I)$

$1.3 \%(46)$

$1.6 \%(54)$ 
The prevalence of CHD also increases, according to an increase of the BMI categories, the highest prevalence of CHD occurs in $3.7 \%$ of participants who had an obesity condition (BMI $\geq 30 \mathrm{~kg} / \mathrm{m} 2$ ). The second highest prevalence of CHD is $3.2 \%$ of participants who had been classified as overweight (BMI between 25 and $<30 \mathrm{~kg} / \mathrm{m} 2$ ). The prevalence of CHD is lower in BMI lower than $18.5 \mathrm{~kg} / \mathrm{m} 2(1.8 \%)$ and BMI between 18.5 and $<25 \mathrm{~kg} / \mathrm{m} 2(2.0 \%)$.

Regarding the lipid profile, the prevalence of CHD in participants with high total cholesterol ( $\geq 200 \mathrm{mg} / \mathrm{dL}$ ) is less than those who had normal levels of total cholesterol (2.2\% vs $2.7 \%)$. In addition, the prevalence of CHD in participants who had a high triglyceride level was higher than those who had an average triglyceride level (2.8\% vs $2.2 \%)$. Furthermore, the prevalence of CHD in people in the population with low HDL-C was higher than in those who had high levels of HDL-C $(2.7 \%$ vs $2.1 \%)$. Moreover, the prevalence of CHD in participants with diabetes mellitus is five times higher than those who did not have diabetes $(6.5 \%$ vs $1.9 \%)$. On the other hand, the prevalence of CHD in regular smokers was lower than in nonsmokers ( $1.3 \%$ vs $2.6 \%)$.

Concerning stroke, the prevalence of stroke in men is $2.5 \%$ and $1.6 \%$ in women. The prevalence of stroke also arises with an increase in age groups. Therefore, the highest prevalence of stroke was in participants who were aged 75 years and over. The second highest prevalence of stroke was in participants aged between 65 and 74 years old and the third highest prevalence in ages between 55 and 64 years old. The prevalence of stroke was less than $1 \%$ of participants who are aged lower than 45 years old. When looking at the prevalence of stroke by BMI categories, it was found that the prevalence of stroke was higher in participants who have a BMI lower than $18.5 \mathrm{~kg} / \mathrm{m} 2$ and second highest in those who were overweight, (BMI between 25 and less than $30 \mathrm{~kg} / \mathrm{m} 2$ ). In the total cholesterol level, there was no difference in the prevalence of stroke. $2.1 \%$ of participants who had high total cholesterol had a stroke condition, and $2.0 \%$ of those who had normal levels of total cholesterol had a stroke. In terms of the triglyceride level, the prevalence of stroke in participants who had a high triglyceride level was higher than those who had an average triglyceride level $(2.6 \%$ vs $1.7 \%)$. Additionally, the prevalence of stroke in participants who had a low HDL-C level was higher than those who had the highest level of HDL-C (2.2\% vs $1.9 \%)$.

Concerning blood pressure, $3.6 \%$ of participants with high blood pressure had stroke conditions, whereas $1.3 \%$ of participants with normal blood pressure had strokes. The prevalence of stroke in participants with diabetes was higher than those who did not have diabetes $(4.4 \%$ vs $1.8 \%)$. Conversely, the prevalence of stroke in the regular smoking group was lower than in the non-smoking group (1.6\% VS.2.1\%).

Table 3 showed the unadjusted and adjusted odds ratios of the associations of the risk factors and CVD conditions. The bivariate analysis and multiple logistic regressions were performed in the NHESIV participants aged 15 years and over.

Table 3 The unadjusted and adjusted odds ratio of the association between risk factors and CVD conditions (CHD and Stroke) in the NHEISV participants aged $\geq 15$ years

CHD (n=466) STROKE $(n=395)$

Risk factors

\begin{tabular}{|c|c|c|c|c|c|c|}
\hline $\begin{array}{l}\text { Unadjusted } \\
\text { odds ratio }\end{array}$ & 5\%Cl & $\begin{array}{l}\text { Adjusted } \\
\text { Odds ratio }\end{array}$ & $95 \% \mathrm{Cl}$ & $\begin{array}{l}\text { Unadjusted Odds } \\
\text { Ratio }\end{array}$ & $5 \% \mathrm{Cl}$ & $\begin{array}{l}\text { Adjusted } \\
\text { Odds ratio }\end{array}$ \\
\hline
\end{tabular}

\section{Gender}

Men

Women

-ref

0.9

Age groups (years)

15-24

25-34

35-44

45-54

55-64

65-74

$\geq 75$

High total cholesterol (TC $\geq 200 \mathrm{mg} / \mathrm{dL}$ )

No* -ref

0.1

0.2

0.5

1.6*

$2.1 *$

$2.7^{*}$

-ref -ref

$0.8-1.1 \quad 0.79$

$\begin{array}{ll} & \text {-ref } \\ 0.03-0.2 & 0.95 \\ 0.09-.3 & 1.79 \\ 0.4-0.7 & 4.9^{*} \\ 1.3-1.9 & 10.53^{*} \\ 1.7-2.6 & 12.25^{*} \\ 2.1-3.3 & 16.9 * \\ & \end{array}$

$\begin{array}{ll} & \text {-ref } \\ 0.24-3.82 & 0.19 \\ 0.58-5.51 & 0.36 \\ 1.74-3.84 & 0.52 \\ 3.85-28.8 & 1.48^{*} \\ 4.48-3.46 & 2.16^{*} \\ 6.14-46.5 & 2.09^{*}\end{array}$

-ref

$0.65-0.97$

0.62

-ref

0.56

$0.45-0.70$

$6.14-46.5-2.09$

-ref

$\begin{array}{lll} & \text {-ref } & \\ 0.09-.38 & 1.28 & 0.44-3.7 \\ 0.24-.55 & 2.31 & 0.94-5.69 \\ 0.36-.75 & 2.96 * & 1.23-7.15 \\ 1.18-.85 & 6.09 * & 2.64-4.06 \\ 1.75-.66 & 7.39 * & 3.21-7.01 \\ 1.55-.59 & 7.63 * & 3.26-7.85\end{array}$

-ref 


\begin{tabular}{|c|c|c|c|c|c|c|c|c|}
\hline \multirow{2}{*}{ Risk } & \multicolumn{4}{|c|}{ CHD $(n=466)$} & \multicolumn{4}{|l|}{ STROKE $(n=395)$} \\
\hline & $\begin{array}{l}\text { Unadjusted } \\
\text { odds ratio }\end{array}$ & $95 \% \mathrm{Cl}$ & $\begin{array}{l}\text { Adjusted } \\
\text { Odds ratio }\end{array}$ & $95 \% \mathrm{Cl}$ & $\begin{array}{l}\text { Unadjusted Odds } \\
\text { Ratio }\end{array}$ & $95 \% \mathrm{Cl}$ & $\begin{array}{l}\text { Adjusted } \\
\text { Odds ratio }\end{array}$ & $95 \% \mathrm{Cl}$ \\
\hline Yes & 0.8 & $0.7-0.98$ & 0.68 & $0.56-0.83$ & $\mathrm{I} .04$ & $0.85-.27$ & 0.92 & $0.74-1.14$ \\
\hline \multicolumn{9}{|c|}{$\begin{array}{l}\text { High triglyceride } \\
\text { (TG } \geq 150 \mathrm{mg} / \mathrm{dL} \text { ) }\end{array}$} \\
\hline No* & -ref & & -ref & & -ref & & -ref & \\
\hline Yes & $1.3^{*}$ & I.I -I.5 & 0.96 & $0.78-1.18$ & $1.49 *$ & $1.22-.82$ & 1.21 & $0.97-|.5|$ \\
\hline \multicolumn{9}{|c|}{$\begin{array}{l}\text { Low HDL-C }(<40 \mathrm{mg} / \\
\mathrm{dL} \text { in men and }<50 \\
\mathrm{mg} / \mathrm{dL} \text { in women) }\end{array}$} \\
\hline No* & -ref & & -ref & & - ref & & -ref & \\
\hline Yes & $1.3^{*}$ & $1.1-1.6$ & 1.03 & $0.84-1.27$ & 1.13 & $0.92-.38$ & 1.01 & $0.8 I-1.26$ \\
\hline \multicolumn{9}{|c|}{$\begin{array}{l}\text { Obesity (BMI } \geq 25 \mathrm{~kg} / \\
\mathrm{m}^{2} \text { ) }\end{array}$} \\
\hline No* & -ref & & -ref & & -ref & & -ref & \\
\hline Yes & $1.7^{*}$ & I.4-2.I & $1.6 *$ & $1.31-1.96$ & I.I & $0.89-.35$ & 1.01 & $0.81-1.25$ \\
\hline \multicolumn{9}{|c|}{ High blood pressure } \\
\hline No* & -ref & & -ref & & -ref & & -ref & \\
\hline Yes & $3.7^{*}$ & 3.I-4.5 & $1.81 *$ & I.47-2.22 & $2.83^{*}$ & $2.31-.46$ & $1.63^{*}$ & $|.3|-2.03$ \\
\hline \multicolumn{9}{|c|}{ Diabetes mellitus } \\
\hline No* & -ref & & -ref & & -ref & & -ref & \\
\hline Yes & $3.5^{*}$ & $2.9-4.3$ & $1.85^{*}$ & $\mid .49-2.31$ & $2.57^{*}$ & $2.02-.28$ & I.59* & $1.23-2.05$ \\
\hline \multicolumn{9}{|c|}{ Regular smoking } \\
\hline No* & - ref & & - ref & & -ref & & -ref & \\
\hline Yes & 0.5 & 0.4-0.7 & 0.57 & $0.41-0.79$ & 0.72 & $0.54-.96$ & 0.64 & $0.47-0.87$ \\
\hline
\end{tabular}

Results showed that the middle and elderly age groups were more affected by CHD. It also showed that the risk of having CHD in the age group 55-64 years is 1.6 times $(\mathrm{OR}=1.6 .95 \% \mathrm{CI} 1.3-1.9)$, while, the risk in the age group $65-74$ years is 2.1 times of $\mathrm{CHD}(\mathrm{OR}=2$. 1. 95\% CI 1.7-2.6). Furthermore, the risk of having CHD in the age group of 75 years and over is 2.7 times $(\mathrm{OR}=2$. 7. 95\% CI 2.1-3.3) compare to the reference group (young age).

The risk factors that were associated with CHD are also associated with stroke. People in the middle age group and the elderly were more likely to have a stroke than people in the younger age group. People at age group 55-64 years were 1.48 times more likely to suffer from a stroke than those who were aged $15-24$ years $(\mathrm{OR}=1.48 .95 \% \mathrm{CI}$ 1.18-1.85). The risk of stroke increased to 2.16 times in the age group 65-74 years $(\mathrm{OR}=2.16 .95 \% \mathrm{CI}=1.75-2.66)$. At age 75 years and over, the risk of stroke was 2.09 times greater than people in the younger age group. When modified for the effects of the other variables, the adjusted odds ratio showed that the middle age groups and above had a significant association with both CHD and stroke.

For the lipid profile, the bivariate analysis showed that participants who had high triglyceride level were 1.3 times more likely to have CHD than those who had an average triglyceride level (OR=1.3, 95\% CI 1.1-1.5). The low level of the good lipid profile such as HDL-C was also associated with CHD. People who had low HDL-C were 1.3 times more likely to have CHD than those who had a high level of HDL-C (OR=1.3, 95\% CI 1.1-1.6). For stroke, the high triglyceride level was associated with stroke. However, the high level of total cholesterol and low level of HDL-C showed no association with stroke. The unadjusted odds ratio showed that people with high triglyceride level were 1.49 times more likely to suffer a stroke than those who had an average triglyceride level $(\mathrm{OR}=1.49,95 \% \mathrm{CI}=1.22$ - 
1.82). However, the adjusted odds ratio of the lipid profiles, such as high total cholesterol, high triglyceride and low HDL-C, did not show association with both CHD and stroke, when controlling the effects of the other variables.

Obesity (BMI $\geq 25 \mathrm{~kg} / \mathrm{m} 2$ ) showed a significant association with CHD in both unadjusted and adjusted odds ratio. The bivariate analysis showed that people with the obesity condition $(\geq 25 \mathrm{~kg} / \mathrm{m} 2)$ were 1.7 times more likely to experience CHD than those who had BMI at the average level $(\mathrm{OR}=1.7,95 \% \mathrm{CI} 1.4-2.1)$. In addition, the adjusted odds ratio of BMI showed that people who were obese were 1.6 times more likely to experience CHD than those who had an average BMI level (OR=1. 6, 95\% CI 1.31-1.96). On the other hand, there was no association between obesity and stroke.

High blood pressure was significantly associated with both CHD and stroke in both bivariate and multivariate analysis. The unadjusted odds ratio showed that people with high blood pressure had 3.7 times the risk of $\mathrm{CHD}$, than those who had normal blood pressure $(\mathrm{OR}=3.7$, $95 \% \mathrm{CI}=3.1-4.5)$ and were 2.83 times more likely to suffer a stroke $(\mathrm{OR}=2.83,95 \% \mathrm{CI}=2.31-3.46)$. Furthermore, the adjusted odds ratio showed that people who had high blood pressure were 1.81 times at greater risk of experiencing $\mathrm{CHD}(\mathrm{OR}=1.81,95 \% \mathrm{CI} 1.47-2.22)$ and 1.63 times more likely to suffer a stroke $(\mathrm{OR}=1.63,95 \%$ CI 1.31 2.03) than those who had normal blood pressure.

Additionally, diabetes also showed a significant association with both CHD and stroke. The unadjusted odds ratio showed that people who had diabetes were 3.5 times more likely to experience CHD than those who did not have diabetes $(\mathrm{OR}=3.5,95 \% \mathrm{CI}=2.9-4.3)$ and 2.57 times more likely to get a stroke $(\mathrm{OR}=2.57,95 \% \mathrm{CI}=2.02-3.28)$. When the multivariate analysis was performed, people who had the diabetes condition were 1.85 times more likely to get $\mathrm{CHD}(\mathrm{OR}=1.85,95 \% \mathrm{CI}$ $1.49-2.31)$ and 1.59 times more likely to get a stroke (OR=1.59, 95\% CI 1.23-2.05). However, there were some risk factors which did not show any significant association of being a risk to CHD and stroke, such as being women, having high cholesterol and regular smoking.

Table 4 presents the association between risk factors and CVD conditions in male participants aged 15 years and over, by using the multiple logistic regression. When controlling for the effects of the other variables, the factors associated with CHD in both men and women were being in the middle and elderly age groups (aged 55 and above), being obese, having high blood pressure and diabetes.

Table 4 The multivariate analysis of the association between risk factors and CVD conditions (CHD and Stroke) in the NHESIV participants aged $\geq 15$ years by gender

\begin{tabular}{|c|c|c|c|c|c|c|c|c|}
\hline \multirow{3}{*}{ Risk factors } & \multicolumn{4}{|c|}{ CHD $(n=466)$} & \multicolumn{4}{|c|}{ Stroke $(n=395)$} \\
\hline & \multicolumn{2}{|c|}{ Men $(n=233)$} & \multicolumn{2}{|c|}{ Women $(n=233)$} & \multicolumn{2}{|c|}{ Men $(n=234)$} & \multicolumn{2}{|c|}{ Women $(n=161)$} \\
\hline & $\begin{array}{l}\text { Adjusted } \\
\text { odds ratio }\end{array}$ & $95 \% \mathrm{Cl}$ & $\begin{array}{l}\text { Adjusted } \\
\text { odds ratio }\end{array}$ & $95 \% \mathrm{Cl}$ & $\begin{array}{l}\text { Adjusted } \\
\text { odds ratio }\end{array}$ & $95 \% \mathrm{Cl}$ & $\begin{array}{l}\text { Adjusted } \\
\text { odds ratio }\end{array}$ & $95 \% \mathrm{Cl}$ \\
\hline \multicolumn{9}{|c|}{ Age groups (years) } \\
\hline $15-24$ & - Ref & & - Ref & & - Ref & & - Ref & \\
\hline $25-34$ & 0.38 & $0.04-3.64$ & 2.44 & $0.25-23.49$ & 0.42 & $0.81-2.19$ & 4.98 & $0.59-41.5$ \\
\hline $35-44$ & 1.67 & $0.43-6.51$ & 2.62 & $0.31-21.85$ & 2.3 & $0.84-6.32$ & 3.23 & $0.39-26.4$ \\
\hline $45-54$ & $4.43^{*}$ & $1.29-15.18$ & 7.33 & $0.97-55.14$ & 2.52 & $0.93-6.87$ & 5.44 & $0.71-41.9$ \\
\hline $55-64$ & $8.49 *$ & $2.62-27.46$ & $16.84^{*}$ & $2.31-123.0$ & 4.78 & $|.88-12.1|$ & $12.22 *$ & $1.65-90.22$ \\
\hline $65-74$ & $9.44 *$ & $2.92-30.49$ & $20.48^{*}$ & $2.81-149.43$ & 6 & $2.38-15.12$ & $13.72 *$ & $1.86-101.29$ \\
\hline$\geq 75$ & $13.67^{*}$ & $4.19-44.61$ & $26.45^{*}$ & $3.59-194.5$ & 5.83 & $2.25-15.07$ & $15.59 *$ & $2.08-116.76$ \\
\hline \multicolumn{9}{|c|}{$\begin{array}{l}\text { High total cholesterol } \\
\text { (TC } \geq 200 \mathrm{mg} / \mathrm{dL})\end{array}$} \\
\hline No & - Ref & & - Ref & & -Ref & & - Ref & \\
\hline Yes & 0.6 & $0.45-0.80$ & 0.77 & $0.58-1.02$ & 1.03 & $0.78-1.37$ & 0.77 & $0.55-1.08$ \\
\hline \multicolumn{9}{|c|}{$\begin{array}{l}\text { High triglyceride } \\
\text { (TG } \geq 150 \mathrm{mg} / \mathrm{dL})\end{array}$} \\
\hline No & - Ref & & - Ref & & - Ref & & - Ref & \\
\hline Yes & 0.89 & $0.66-1.21$ & 1.01 & $0.75-1.34$ & 1.02 & $0.76-1.36$ & $1.51^{*}$ & $1.07-2.13$ \\
\hline $\begin{array}{l}\text { Low HDL-C } \\
\text { in male and } \\
\text { in female) }\end{array}$ & & & & & & & & \\
\hline
\end{tabular}




\begin{tabular}{|c|c|c|c|c|c|c|c|c|}
\hline \multirow{3}{*}{ Risk factors } & \multicolumn{4}{|c|}{ CHD (n=466) } & \multicolumn{4}{|c|}{ Stroke $(n=395)$} \\
\hline & \multicolumn{2}{|c|}{ Men $(n=233)$} & \multicolumn{2}{|c|}{ Women $(n=233)$} & \multicolumn{2}{|c|}{ Men $(n=234)$} & \multicolumn{2}{|c|}{ Women $(n=161)$} \\
\hline & $\begin{array}{l}\text { Adjusted } \\
\text { odds ratio }\end{array}$ & $95 \% \mathrm{Cl}$ & $\begin{array}{l}\text { Adjusted } \\
\text { odds ratio }\end{array}$ & $95 \% \mathrm{Cl}$ & $\begin{array}{l}\text { Adjusted } \\
\text { odds ratio }\end{array}$ & $95 \% \mathrm{Cl}$ & $\begin{array}{l}\text { Adjusted } \\
\text { odds ratio }\end{array}$ & $95 \% \mathrm{Cl}$ \\
\hline No & -Ref & & -Ref & & $-\operatorname{Ref}$ & & - Ref & \\
\hline Yes & 1.01 & $0.81-1.45$ & 0.98 & $0.73-I .31$ & 1.13 & $0.84-I .52$ & 0.87 & $0.61-1.23$ \\
\hline \multicolumn{9}{|c|}{ Obesity (BMI $\left.\geq 25 \mathrm{~kg} / \mathrm{m}^{2}\right)$} \\
\hline No & -Ref & & -Ref & & $-\operatorname{Ref}$ & & - Ref & \\
\hline Yes & 1.74 & I.30-2.32 & 1.49 & I.12-1.97 & 0.91 & $0.67-1.24$ & 1.15 & $0.83-1.59$ \\
\hline \multicolumn{9}{|c|}{ High blood pressure } \\
\hline No & -Ref & & -Ref & & -Ref & & - Ref & \\
\hline Yes & 1.72 & I.29-2.30 & 1.89 & I.42-2.54 & 1.52 & $1.15-2.03$ & 1.8 & $1.27-2.55$ \\
\hline \multicolumn{9}{|c|}{ Diabetes mellitus } \\
\hline No & - Ref & & - Ref & & $-\operatorname{Ref}$ & & - Ref & \\
\hline Yes & 1.68 & $1.21-2.33$ & 2.02 & I.49-2.73 & 1.56 & $|| I-2.2 \mid$. & 1.59 & $1.09-2.32$ \\
\hline \multicolumn{9}{|c|}{ Regular smoking } \\
\hline No & -Ref & & -Ref & & -Ref & & -Ref & \\
\hline
\end{tabular}

The risk of getting CHD in men and women increased with an advance in age. Men aged 55-64 years had 8.49 times higher risk of $\mathrm{CHD}(\mathrm{OR}=8.49,95 \% \mathrm{CI} 2.62-27.46)$ and men aged 65-74 years were 9.44 times more likely to have a risk of CHD than those who were aged 15-24 years $(\mathrm{OR}=9.44,95 \% \mathrm{CI} 2.92-30.49)$. The risk of $\mathrm{CHD}$ was highest at age 75 years and above which was 13.67 times higher than those who were aged 15-24 years $(\mathrm{OR}=13$. 67, 95\% CI 4.19 44.61). In addition, women who were in the middle age and elderly age groups were more likely to get both CHD and stroke and the risk increased with an advance in age. Women aged 55-64 years had 16.8 times the risk $(\mathrm{OR}=16.8,95 \% \mathrm{CI} 2.3-123.0)$, at age $65-74$ years had 20.5 times the risk $(\mathrm{OR}=20.5,95 \% \mathrm{CI} 2.81-149.43)$ and at age 75 years and over had 26.45 times the risk $(\mathrm{OR}=26.45,95 \%$ CI 3.59 194.5) of getting CHD than women aged 15-24 years. Furthermore, men who had an obesity condition (BMI $\geq 25 \mathrm{~kg} / \mathrm{m} 2)$ were 1.74 times more likely to experience CHD than those who had a normal BMI $(\mathrm{OR}=1.74,95 \%$ CI $1.30-2.32)$. Women who were obese $(\mathrm{BMI} \geq 25$ $\mathrm{kg} / \mathrm{m} 2$ ) were 1.49 times more likely to experience CHD than those who had a normal BMI (OR=1. 49, 95\% CI 1.12-1.97). Men who had high blood pressure were 1.72 times more likely to experience CHD than those who had normal blood pressure (OR=1. 72, 95\% CI 1.29 - 2.30). Women who had high blood pressure were 1.89 times more likely to experience CHD than those who had normal blood pressure $(\mathrm{OR}=1.89,95 \% \mathrm{CI}=1.42-2.54)$. Additionally, men who had diabetes were 1.68 times more likely to get CHD than those who did not have diabetes. Women who had diabetes were 2.02 times more likely to experience CHD than those who did not have diabetes. However, dyslipidaemia and being regular smokers did not show any significant association with CHD in both men and women.

The factors associated with stroke in both men and women were being in the middle and elderly age groups, having high blood pressure and diabetes. The middle and elderly age groups showed significant association to stroke in men as well as CHD. Men aged 55-64 years had 4.78 times the risk of experiencing $\mathrm{CHD}(\mathrm{OR}=4.78,95 \% \mathrm{CI}$ $1.88-12.11)$ than men in the younger age group (15-24 years). The risk of stroke in men was highest at age 65-74 years, which is six times higher than the younger age group $(\mathrm{OR}=6.00,95 \%$ CI 2.38-15.12). For women, the age group that showed association with stroke were being aged 55-64 years, 65-74 years and 75 years and above. The adjusted odds ratio were presented as following 55-64 years $(\mathrm{OR}=12$. $22,95 \%$ CI $1.65-90.22), 65-74$ years $(\mathrm{OR}=13$. 72, 95\% CI 1.86 $101.29)$ and 75 years and above (OR=15. 59, 95\% CI 2.08-116.76). Also, men who had high blood pressure were 1.52 times more likely to experience a stroke than those who had normal blood pressure $(\mathrm{OR}=1.52,95 \%$ CI 1.15-2.03). Women who had high blood pressure were 1.8 times more likely to experience a stroke than those who had normal blood pressure (OR=1.8, 95\% CI 1.27-2.55). Men who had a diabetic condition also had a 1.56 times greater risk of experiencing a stroke than those who did not have diabetes $(\mathrm{OR}=1.56,95 \% \mathrm{CI} 1.11$ 2.21). Women with a diabetic condition were 1.59 times more likely to experience a stroke than those who did not have diabetes $(\mathrm{OR}=1.59$, 
95\% CI 1.09-2.32). Furthermore, the factor that showed a significant association with stroke only in women was a high triglyceride level. Women who had a high triglyceride level were 1.51 times more likely to experience a stroke than those who had an average triglyceride level $(\mathrm{OR}=1.51,95 \%$ CI 1.07-2.13).

On the other hand, dyslipidemia, obesity and regular smoker factors were not associated with stroke, when controlled against the effects of the other variables in men. Furthermore, there were no associations found between high total cholesterol, low HDL-C, being obese, being a regular smoker and stroke in women.

\section{Discussion}

This was an analysis of the national cross-sectional data which was collected during 2008-2009. The strength of the NHESIV is that it is the most extensive national representative cross-sectional survey, which can present the health status of the general Thai population during that period. However, there are some limitations. Although the bivariate analysis and multivariate analysis present the associations between the risk factors and the CVD conditions, it is not able to perform the causal relationship between these risk factors and CVD. Therefore, the results do not show the cause and effect of risk factors to CVD.

The risk factors that show no association with CHD or stroke in both bivariate analysis and multivariate analysis are high total cholesterol and regular smoking. This might be because people who already had CHD or stroke had received treatment to control their total blood cholesterol, such as obtaining a cholesterol-lowering drug. Additionally, once they had been diagnosed that they had CHD or stroke, they also changed their unhealthy lifestyle and stopped smoking.

When adjusted for an effect of the other variables in both men and women, the risk factors that are associated with CHD, in both genders, are being in the middle and elderly age groups, having high triglyceride levels, having low HDL-C, being obese (BMI $\geq 25 \mathrm{~kg}$ / $\mathrm{m} 2$ ), having high blood pressure and diabetes. The analysis did not find significant associations with higher total cholesterol and regular smoking, and the result also showed no association in the bivariate analysis. However, when analysing the association with gender, all lipid profiles were not related to CHD. This might be due to the limited number of CHD cases when performing the analysis by gender, which was not a large enough sample to show any significant association.

Furthermore, the factors associated with stroke were being in the middle age and elderly age groups, having high blood pressure and diabetes. There was no association between all lipid profiles, obesity and regular smoking when performing the multivariate analysis in both genders. However, having high triglyceride level showed a significant association with stroke but only in women.

\section{Conclusions}

Although the middle age and elderly age groups show a significant association with both CHD and stroke in women, the $95 \%$ confidence interval among women was vast across the age groups factor. This was because there are very few numbers of stroke cases in the reference age groups of 15-24 years and the number of stroke cases in women aged 55 years and over, was higher than in the other age groups. Another reason was the NHESIV randomly selected the sampling in the general population; there are few numbers of CHD and stroke cases found in the survey. If there were a more significant number of cases, it might have shown a more precise association in $95 \%$ confidence interval.

\section{References}

I. International Health Policy Program. Burden of Diseases and Injury in Thailand 2009. The graphico system; 2012.

2. Hubert HB, Feinleib M, McNAMARA PM, Castelli WP, Chalon J. Obesity as an Independent Risk Factor for Cardiovascular Disease:A 26-year Followup of Participants in the Framingham Heart Study. Survey of Anesthesiology. 1984;28(I): II.

3. Bureau of Non-Communicable Disease, Department of Disease Control, Ministry of Public Health. Annual Report 2009. Thailand: Office of Veterans Affairs Printing Organization under the Royal Patronage; 2010.

4. Asia Pacific Cohort Studies Collaboration. Blood pressure and cardiovascular disease in the Asia Pacific region. Journal of hypertension. 2003;2I(4):707-7I6.

5. Ezzati M, Lopez AD, Rodgers A,Vander Hoorn S, Murray CJ, Group CRAC. Selected major risk factors and global and regional burden of disease. The Lancet. 2002;360(9343): 1347-1360.

6. Huxley R, Barzi F, Woodward M. Excess risk of fatal coronary heart disease associated with diabetes in men and women: meta-analysis of 37 prospective cohort studies. Bmj. 2006;332(7533):73-78.

7. Lee J, Heng D, Ma S, Chew S-K, Hughes K, Tai E-S. The metabolic syndrome and mortality: the Singapore Cardiovascular Cohort Study. Clinical endocrinology. 2008;69(2):225-230.

8. Anand SS, Islam S, Rosengren A, et al. Risk factors for myocardial infarction in women and men: insights from the INTERHEART study. European heart journal. 2008;29(7):932-940.

9. Ministry of Public Health, Health Systems Research Institute, National Health Security Office, Thai Health Promotion Foundation. Thailand National Health and Examination Survey IV Report 2008-2009. Thailand

10. Sritara P, Cheepudomwit S, Chapman N, et al. Twelve-year changes in vascular risk factors and their associations with mortality in a cohort of 3499 Thais: the Electricity Generating Authority of Thailand Study. International journal of epidemiology. 2003;.

II. World Health Organization, Regional Office for South East Asia. Global Adult Tobacco Survey: Thailand Report 2009. Thailand: WHO Press; 2009. http://www.searo.who.int/LinkFiles/Tobacco_Free_Initiative_GATS-ThaCountry-Report-09.pdf.Accessed August 8, 2015.

12. Lindsay GM, Gaw A. Coronary Heart Disease Prevention:A Handbook for the Health-Care Team. Elsevier Health Sciences; 2004.

13. Mackay J, Menash GA, Mendis S, Greenlund K. The Altas of Heart Disease and Stroke. Geneva:World Health Organization; 2004.

14. Healey J, ed. Cardiovascular Health. Thirroul, NSW, Australia: Spinney Press; 2012.

15. Luepker RV, Apple FS, Christenson RH, et al. Case definitions for acute coronary heart disease in epidemiology and clinical research studies: a statement from the AHA Council on Epidemiology and Prevention; AHA Statistics Committee; World Heart Federation Council on Epidemiology and Prevention; the European Society of Cardiology Working Group on Epidemiology and Prevention; Centers for Disease Control and Prevention; and the National Heart, Lung, and Blood Institute. Circulation. 2003; 108(20):2543-2549.

16. Thygesen K, Alpert JS, Jaffe AS, Simoons ML, Chaitman BR, White HD. Third Universal Definition of Myocardial Infarction. Circulation. 20I2; I 26(I6):2020-2035. doi:I0. I I6I/CIR.0b0I3e3 I826el058
Submit your Article | www.ologyjournals.com/submit-article

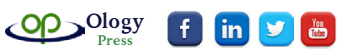

Citation: Inthawong R, Khatab K, Whitfield M, et al. Risk factors associated with Cardiovascular Disease (CVD) in Thailand from the 4th National Health Examination Survey 2008-2009. Biostatistics Epidemiol Int J. (20I9);2(I):I3-22. DOI: 10.3088 I/beij.000I4 
17. Sacco RL, Kasner SE, Broderick JP, et al. An updated definition of stroke for the 2lst century: a statement for healthcare professionals from the American Heart Association/American Stroke Association. Stroke. 2013;44(7):2064-2089.

18. American Heart Association. Ischemic Strokes (Clots). http://www. strokeassociation.org/STROKEORG/about stroke/TypesofStroke/ IschemicClots/Ischemic-Strokes-Clots_UCM_310939_Article.jsp. Published 2013. Accessed November 13, $20 \overline{1} 5$.
19. American Heart Association. Hemorrhagic Strokes (Bleeds). http:// www.strokeassociation.org/STROKEORG/about stroke/TypesofStroke/ HemorrhagicBleeds/Hemorrhagic-Strokes-Bleeds_UCM_310940_ Article.jsp. Published 20I3.Accessed February 10, 2015.

20. Sorensen AG, Ay H. Transient ischemic attack: definition, diagnosis, and risk stratification. Neuroimaging Clinics. 20 I I;2 I (2):303-3 I 3. 